\title{
Editorial
}

\section{The role of human resources in the computerized factory}

\author{
Donald GERWIN \\ University of Wisconsin-Milwaukee, USA \\ Arndt SORGE \\ Wissenschaftszentrum Berlin, West Germany \\ Malcolm WARNER \\ Brunel University, West London, UK
}

We challenge the appropriateness and feasibility of a wholesale substitution of computerized automation for human resources in the factory of the future. Employees will exert greater influence than ever before because of the complexity, cost and critical role of the equipment with which they work. This view is supported through examples of the significance of human inputs in almost every level and function of the automated factory including management, the work force, and staff and service occupations. The truly effective computerized factory will consist of a well balanced interaction of human and technical elements.

Keywords: Human resource management, factory of the future, computer-aided manufacturing, manufacturing strategy, discrete parts manufacturing, innovation process, work organization.

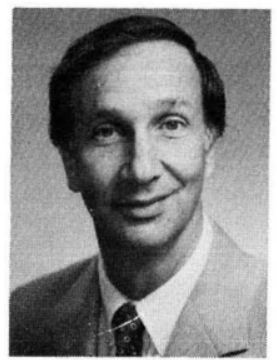

tems Management.
Donald Gerwin is Research Professor at the School of Business Administration, University of Wisconsin-Milwaukee. He received his Ph.D. from Carnegie-Mellon University. His research interests are in the strategic and organizational aspects of managing new production technology. He has been invited to conduct research has been invited to conduct research Austria and Norway. He is an associate editor of Management Science and on the editorial board of Human Sys.

North-Holland

Human Systems Management 6 (1986) 193-196
Over the last ten to fifteen years computerized automation has worked its way into the design, fabrication, assembly, material handling, storage, inspection, and control activities of our factories. Computer-aided manufacturing, automated material handling, robotics and expert systems are becoming essential ingredients of discrete parts manufacturing. Computer-integrated manufacturing is beginning to combine these bits and pieces into a meaningful whole. The computer-integrated

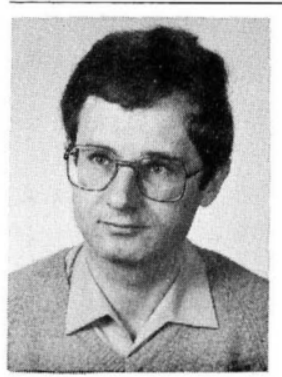

Arndt Sorge is a Fellow and Research Coordinator at the Labor Market Policy Unit, Wissenschaftszentrum Berlin, Germany. Previously, he was Lecturer in Sociology, University of Münster, West Germany (1972-1975) and Research Fellow, St Anthony's College, Oxford (1975-1977). His work has included cross-national comparisons of work organization, vocational training and industrial relations in Western Europe. Since 1978, his research has been focused on applications of microelectronics in manufacturing. He has co-authored (with Hartmann, Warner and Nicholas) Microelectronics and Manpower in Manufacturing (Gower Press: Aldershot, 1983) and is just publishing Comparative Factory Organization: An Anglo-German Comparison of Management and Manpower in Manufacturing with Malcolm Warner (Gower Press, Aldershot, end of 1986). Currently, he is involved in research on applications of microelectronics in products and changes of training and skills.

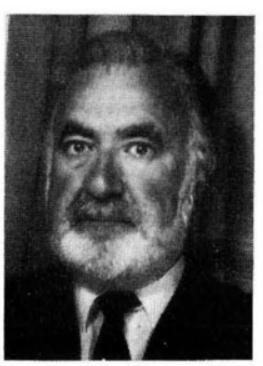

Malcolm Warner was born in 1937 in Manchester; and was educated at Trinity College, Cambridge where he completed his Undergraduate and Doctoral studies. $\mathrm{He}$ has been involved in research on both sides of the Atlantic at both Stanford and Columbia Universities, as well as at the London Business School. Since 1973, he has been Professor and Research Coordinator at Henley: the Management College, and Brunel: the University of West London, England. His main teaching and research interests are in the area of organizational behavior and industrial relations. His most recent publications have dealt with microelectronics and manpower in manufacturing. He is a former Convenor of the Industrial Sociology Group of the British Sociological Association. 
automated factory, practically free of human activity, has been promised to us by the turn of the century [5].

Many managers and engineers view these trends as inevitable and desirable. They believe that the primary objective of manufacturing is efficiency and that the way to achieve it is through predictability and control. Human behavior is a major source of uncertainty which can be eliminated through computerized automation. These views are reinforced by increases in labor costs relative to productivity, and the tendency of our better educated workforce to avoid the tedious jobs associated with manufacturing.

This special issue is devoted to challenging the appropriateness and feasibility of a wholesale substitution of computerized automation for human inputs. We see employees in the factory of the future exerting greater influence than ever before because of the complexity, cost, and critical role of the equipment with which they work. Further, we believe that human inputs will still be required at almost every level and in almost every function of the automated factory. Consequently, the significant human resource issue will not be how fast can people be eliminated, but where exactly will they be needed, what skills and attitudes will they need, and how will they be organized.

The justifications for this alternative view result from standing the previously mentioned managerial beliefs on their heads. First of all, recent studies have called into question the use of efficiency as manufacturing's paramount criterion. Excessive concentration on efficiency is bound to limit the attainment of other objectives such as innovation. Abernathy [1] found that over time the increasing productivity of the American auto industry retarded its ability to introduce new products and processes. Further, industrialized nations should currently be more concerned about fostering innovation rather than efficiency. Reich [7] sees the solution to America's competitive problems in a turning away from capital-intensive, high-volume, standardized production in favor of labor-intensive, low-volume, customized production.

Second, human behavior if properly managed can be uncertainty reducing rather than uncertainty enhancing. Employees are a knowledgeable source of solutions to problems. They represent a flexible resource which can readily be deployed to handle emergencies. They reduce the need for excessive reliance on complex equipment, the reliability of which is bound to be low. Managements which treat employees as valuable contributors look upon high wages as an investment that will more than pay for itself in the long run. Employees who believe they are making valuable contributions have no desire to leave manufacturing for more challenging tasks elsewhere.

To explore these issues in more detail we focus on some areas in which human inputs will be essential for the effective functioning of computerized automation. First, consider strategy. The necessity for compatibility between a technology's characteristics and a strategy's aims has only recently been established $[3,6,9]$. Computerized automation should have particularly strong links with strategy because of its flexibility characteristics [2]. The ability to produce a number of different products at the same point in time facilitates product diversity, the ability to change over from an old product to a new one fosters product innovation, and being able to readily implement design changes in a given product stimulates being responsive to customer needs. In brief, computerized automation can help reverse the trend to more efficient but less flexible productive units.

Taking advantage of the new opportunities calls for some fundamental changes on the part of senior managers. They will have to forge a strategic consensus early on, in order to know which aspects of flexibility a company requires. It will be necessary for them to inquire more deeply into the technical aspects of equipment proposals to ensure that a match exists with strategic needs. This means knowing more about what equipment can do, how it functions, and what it requires [9]. They will have to learn to cope with more uncertain operating conditions. With a transfer line the amount of daily production can be readily determined in advance. With a flexible manufacturing system daily production depends upon several partially controllable factors.

Second, consider organization and training of the workforce. Shouldn't these issues have less significance as capital reflected in computerized automation replaces labor? On the contrary, the workers who remain will assume more power due to their control over the controls of automated manufacturing processes [4]. Some companies will be unwilling to accept this situation. Where, for 
example, efficiency assumptions exist or there is a history of labor relations problems, management will tend to adopt traditional work organization and training approaches in order to circumscribe workers' power. Those firms which can accept the new realities will be led into novel ways of organizing and training [10].

Workers will need a broader range of skills in order to perform a greater variety of tasks as they adopt a systems approach to the new technology. Many technicians already work in common design networks and have to cooperate across job boundaries with theoretical knowledge matched by diagnostic skills. There may also be a need to integrate employees doing non-routine and routine computer-assisted work, and develop new job designs to avoid polarization. Mixtures of operator and maintenance skills will also have to be integrated at the sub-technician level, combining part-programming CNC machine-tools for example, with coping with faults or breakdowns. Mechanical and electrical/electronic skills will have to overlap.

As the hybridization process proceeds, more diverse training will be needed with experienced workers taking over part of the instructional load. It is quite likely that as training requires greater investment by employing organizations, they will be selective as to who they recruit only taking on those with the most appropriate prior qualifications and aptitudes. They will try to minimize the risks of selecting those who appear to be optimal 'training-investments'. At the same time, training costs will rise relative to other employment costs. With new technology this may represent a disincentive to recruit as it will add to the capital cost per job. The absolute length of training will be less problematic than the need to up-date ideas as existing knowledge becomes obsolete at a faster rate.

Work organization is likely to be based on socio-technical principles to facilitate workers learning how to deal with the unexpected [4]. At the extreme the unit of organization will be the work group. Teams provide a range of roles through which new skills can be learned. Workers will engage in planning, maintenance and control activities while supervisors act as consultants. They will be paid salaries based on the number of skills a person has learned and will evaluate each other for raises. Workers and managers will jointly assess overall factory performance through special committees.

Third, consider the innovation process in which computerized technology is introduced to an organization. The problems encountered during innovation appear to be more managerial than technical in nature [8]. It is the motivation, skills, attitudes, and organization of those people involved in adoption and implementation which determine whether computerized automation is successfully introduced.

For example, there exists a need for a 'process champion', a person who believes enough in the new technology that he or she is willing to accept the risks of trying to get it accepted. Champions must deal with people who may be satisfied with the status quo, fear uncertainty or lack technical competence. Consequently, they must possess courage, persistence, an ability to translate technical detail into the vernacular, and political skills. They must know how to organize resources, solve problems, project confidence, and bargain for allies. Managers need to be able to identify these people and provide them with sufficient resources.

The substantial benefits of computerized automation tend to have major qualitative aspects. It is difficult to express lead time reductions, quality improvements, and flexibility increases in measurable terms. Costs, on the other hand, tend to be more easily measured. Over-reliance on traditional justification procedures will therefore tend to eliminate the new technology from consideration. The adoption decision must be made using a considerable amount of human judgment if computerized automation is to be given a fair hearing.

During the innovation period it is necessary to develop a sophisticated support team. First-line supervisors require extensive technical knowledge. They also need interpersonal skills to motivate workers and to interact with staff and service people. Accountants have to develop and become accustomed to new control systems based on machining time instead of direct labor hours. Personnel specialists must devise new pay plans based on planning, coordinating, and learning as opposed to producing outputs. However, these and other necessary changes can occur only if a company's support people have been given sufficient prior exposure to advanced manufacturing technology. Otherwise, the required leap may be too great.

We hope these examples are sufficient to dem- 
onstrate how a firm will become even more dependent upon human resources as it switches to programmable manufacturing technology. The effective computer-automated factory will not be a smoothly functioning machine. It will be a system of interacting human and technical elements.

\section{References}

[1] Abernathy, W.J., The productivity dilemma (The Johns Hopkins University Press, Baltimore, MD, 1978).

[2] Gerwin, D., Do's and don'ts of computerized manufacturing, Harvard Business Review 60 (1982) 107-116.

[3] Hayes, R.H. and S.C. Wheelwright, Restoring our competitive edge (Wiley, New York, 1984).
[4] Hirschhorn, L., Beyond mechanization: work and technology in a postindustrial age (The MIT Press, Cambridge, MA, 1984).

[5] Merchant, M.E., The inexorable push for automated production, Production Engineering (1977) 44-49.

[6] Porter, M.E., The technological dimension of competitive strategy, in: R.S. Rosenbloom, Ed., Research on technological innovation, management, and policy (JAI Press, Greenwich, CT, 1983) 1-34.

[7] Reich, R.B., The next american frontier (Times Books, New York, 1983).

[8] Rosenthal, S., Progress toward the factory of the future, Journal of Operations Management 4 (1984) 203-229.

[9] Skinner, W., Manufacturing in the corporate strategy (Wiley, New York, 1978).

[10] Sorge, A., G. Hartmann, M. Warner and I. Nicholas, Microelectronics and manpower in manufacturing (Gower Press, Aldershot, 1983). 